\title{
Bleeding Tendency Caused by the Deposit of Amyloid Substance in the Perivascular Region
}

\author{
Yoshiaki Hoshino, Kiyohiko Hatake, Kazuo Muroi, Saburo Tsunoda, \\ Toshiyuki Suzuki, Akiyoshi Mrwa, Shinobu SaKamoto and Yasusada Miura
}

\begin{abstract}
A 55-year-old woman, who had systemic amyloidosis associated with multiple myeloma, had sudden development of hematomas of her lip and upper eye lid. There was no evidence of deterioration of multiple myeloma, thrombocytopenia nor deficiency of coagulation factors. Biopsy specimen showed the deposit of amyloid substance in the dermis and perivascular region. The bleeding tendency in this patient with myeloma was likely due to the deposit of amyloid substance in the vascular wall; improvement was achieved with administration of hemostatic agents.

(Internal Medicine 32: 879-881, 1993)
\end{abstract}

Key words: multiple myeloma, amyloidosis, hemostatic agent

\section{Introduction}

Amyloidosis is one of the common complications of multiple myeloma. Amyloid substance is classified into two types: amyloid L (AL) which mainly consists of light chains and amyloid A(AA) mainly consisting of protein A (1). Amyloidosis associated with multiple myeloma is mainly AL. The bleeding tendency in amyloidosis is usually due to a deficiency of factor $\mathrm{X}$, intravascular coagulopathy, deposit of amyloid substance and so on $(1,2)$. We report here the bleeding tendency in a case of amyloidosis with multiple myeloma probably due to deposits of amyloid substance in the perivascular region; improvement was achieved with hemostatic agents.

\section{Case Report}

A 55-year-old house wife was admitted to our hospital because of hematomas on her lower lip and left upper eye lid on April 2, 1991. She had a past history of dysentery at age 7 years, an appendicits at age 20 years and pulmonary tuberculosis at age 22 years. In July 1988, she found yellow papules on the back of her neck, and consulted her family physician. She received steroid ointment therapy, however there was no improvement. In November 1988, she noticed a bleeding tendency in her oral cavity and her fingers. She was admitted to the Department of Dermatology of our hospital in May 1989.

The skin biopsy revealed the presence of amyloidosis. Immunoelectrophoresis of urine showed an $\mathrm{M}$ component of
Bence Jones protein $\kappa$ type. Myeloma cells occupied $31 \%$ of nucleated cells in the bone marrow. She was diagnosed as having multiple myeloma associated with amyloidosis and was discharged from the hospital on August 12, 1989, receiving periodical chemotherapy of vincristine and melphalan thereafter.

She showed a good response, and had been doing well until April 2, 1991, when hematomas suddenly emerged on her lower lip and upper eye lid with no apparent cause. She was admitted to our hospital on emergency. Physical findings on admission revealed that she had hematomas on her lip and eye lid, and she had yellow, glossy papules on her upper limb and trunk. There was no abnormal finding in her chest, abdomen nor nervous system. Slight leukocytopenia and anemia were observed, but no significant abnormal data were observed in prothrombin time (PT), activated partial thromboplastin time (APTT), $\alpha_{2^{-}}$ plasmin inhibitor $\left(\alpha_{2}-\mathrm{PI}\right)$, plasminogen activity, fibrin degradation product (FDP) and bleeding time (Table 1). After admission, we treated her bleeding tendency with carbazochrome sodium sulfate and tranexamic acid. There was no newly forming hematomas nor ecchymosis. The hematomas came off as clots after one week. In iliac bone marrow, the percentage of myeloma cells was $6.2 \%$ of nucleated cells, and the amount of $\mathrm{M}$ component determined by immunoelectrophoresis in her urine did not increase as compared with the previous data. As to her systemic amyloidosis, there was no evidence of cardiac amyloidosis by echogram nor thyroid dysfunction. Skin biopsy specimen showed deposit of amyloid in dermis (Fig. 1).

From the Division of Hematology, the Department of Medicine, Jichi Medical School, Tochigi

Received for publication July 19, 1993; Accepted for publication October 25, 1993

Reprint requests should be addressed to Dr. Yoshiaki Hoshino, the Division of Hematology, the Department of Internal Medicine, Jichi Medical School, 3311 1 Yakushiji Minamikawachi-machi Kawachi-gun, Tochigi 329-04 


\section{HosHino et al}

Table 1. Laboratory Data on Admission (April 2, 1991)

\begin{tabular}{|c|c|c|c|}
\hline \multicolumn{2}{|l|}{ Blood cell count } & \multicolumn{2}{|l|}{ Biochemistry } \\
\hline WBC & $3.9 \times 10^{3} / \mu \mathrm{l}$ & Total protein & \multirow{2}{*}{$\begin{array}{r}5.6 \mathrm{~g} / \mathrm{dl} \\
70.3 \%\end{array}$} \\
\hline band neutrophil & $19 \%$ & Albumin & \\
\hline segmented neutrop & $63 \%$ & $\alpha_{1}$-globulin & $3.6 \%$ \\
\hline monocyte & $4 \%$ & $\alpha_{2}$-globulin & $8.3 \%$ \\
\hline lymphocyte & $14 \%$ & B-globulin & $8.5 \%$ \\
\hline $\mathrm{Hb}$ & $9.0 \mathrm{~g} / \mathrm{dl}$ & $\gamma$-globulin & $9.3 \%$ \\
\hline $\mathrm{Ht}$ & $26.1 \%$ & Total bilirubin & $0.77 \mathrm{mg} / \mathrm{d}$ \\
\hline $\mathrm{RBC}$ & $2.5 \times 10^{6} / \mu \mathrm{l}$ & $\gamma$-GTP & $18 \mathrm{mU} / \mathrm{m}$ \\
\hline Platelet & $9.4 \times 10^{4} / \mu \mathrm{l}$ & ALP & $173 \mathrm{mU} / \mathrm{m}$ \\
\hline Coagulation & & GOT & $17 \mathrm{mU} / \mathrm{ml}$ \\
\hline Prothrombin time & $10.5 \mathrm{~s}$ & GPT & $12 \mathrm{mU} / \mathrm{m}$ \\
\hline (con & trol $12.1 \mathrm{~s})$ & LDH & $404 \mathrm{mU} / \mathrm{ml}$ \\
\hline Activated partial thro & omboplastin & CPK & $68 \mathrm{mU} / \mathrm{ml}$ \\
\hline time & $39.1 \mathrm{~s}$ & Amylase & 87 Somogy \\
\hline (con & trol $35.9 \mathrm{~s})$ & BUN & $18 \mathrm{mg} / \mathrm{d}$ \\
\hline Fibrinogen & $347 \mathrm{mg} / \mathrm{dl}$ & Creatinine & $0.7 \mathrm{mg} / \mathrm{d}$ \\
\hline Factor XIII activity & $73 \%$ & Uric acid & $5.0 \mathrm{mg} / \mathrm{d}$ \\
\hline Bleeding time & $2 \mathrm{~m}$ in $30 \mathrm{~s}$ & $\mathrm{Na}$ & $145 \mathrm{mEq} / \mathrm{l}$ \\
\hline $\mathrm{FDP}<10 \mu \mathrm{g} / \mathrm{ml}$ & & $\mathrm{K}$ & $4.0 \mathrm{mEq} / \mathrm{l}$ \\
\hline (D-dimer $<$ & $200 \mathrm{ng} / \mathrm{ml})$ & $\mathrm{Cl}$ & $112 \mathrm{mEq} / \mathrm{l}$ \\
\hline Plasminogen activity & $80.7 \%$ & $\mathrm{Ca}$ & $9.2 \mathrm{mg} / \mathrm{dl}$ \\
\hline $\mathrm{a}_{2}$-plasmin inhibitor & activity & $\mathrm{P}$ & $3.1 \mathrm{mg} / \mathrm{d}$ \\
\hline & $87.5 \%$ & CRP & $0.117 \mathrm{mg} / \mathrm{d}$ \\
\hline Bone marrow & & Immunoglobulin & \\
\hline NCC & $12.7 \times 10^{4} / \mu 1$ & $\operatorname{IgG}$ & $734 \mathrm{mg} / \mathrm{d}$ \\
\hline Megakaryocyte & $56 / \mu 1$ & $\operatorname{IgA}$ & $42 \mathrm{mg} / \mathrm{dl}$ \\
\hline Myeloid & & $\mathrm{IgM}$ & $29 \mathrm{mg} / \mathrm{d}$ \\
\hline Myeloblast & $1.2 \%$ & & \\
\hline Promyelocyte & $1.4 \%$ & & \\
\hline Myelocyte & $18.8 \%$ & & \\
\hline Metamyelocyte & $7.2 \%$ & & \\
\hline Band neutrophil & $25.8 \%$ & & \\
\hline Segmented neutrop & ohil $3.2 \%$ & & \\
\hline Eosinophil & $2.4 \%$ & & \\
\hline Basophil & $0.2 \%$ & & \\
\hline Monocyte & $1.2 \%$ & & \\
\hline Plasma cell & $6.2 \%$ & & \\
\hline Erythroid & $18.8 \%$ & & \\
\hline Reticulum cell & $1.4 \%$ & & \\
\hline
\end{tabular}

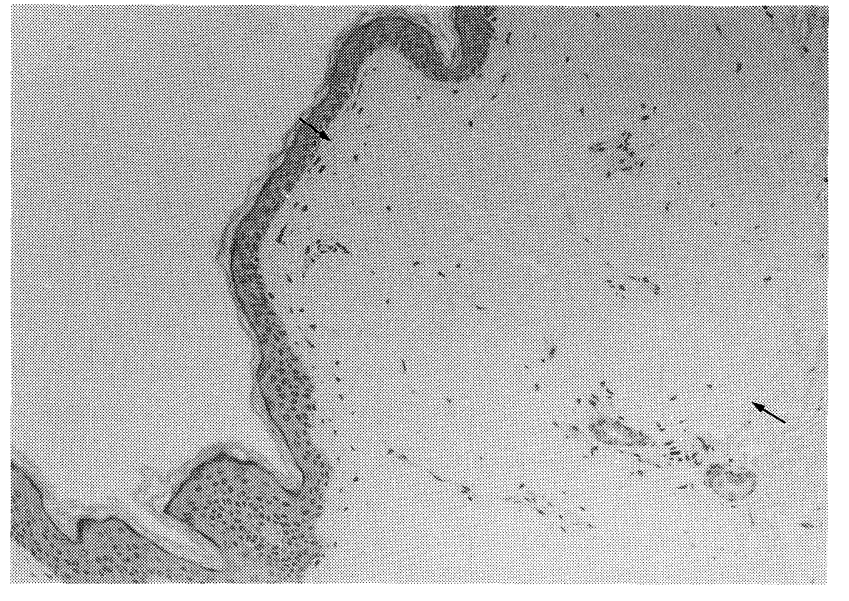

Fig. 1. The biopsy specimen of her skin. Arrows indicate the amyloid substance in the dermis (HE stain, $\times 200$ ).

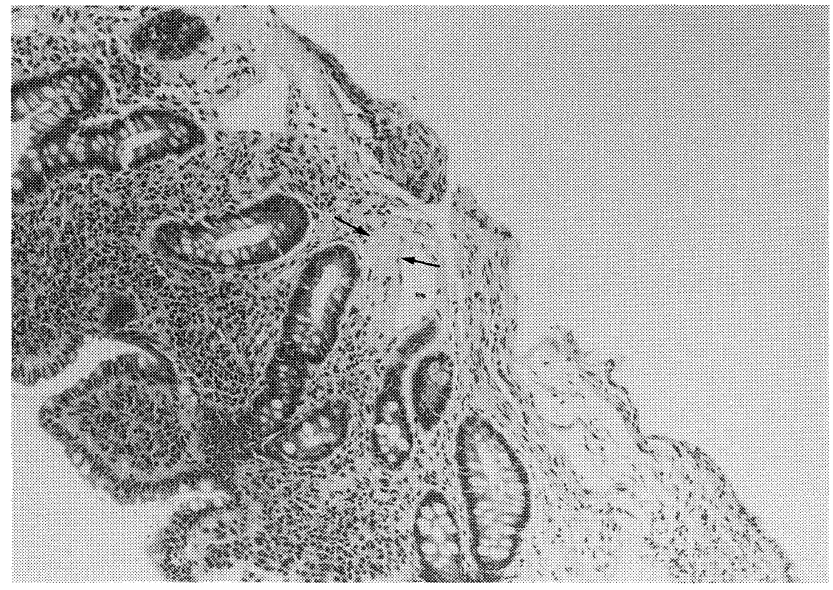

Fig. 2. The biopsy specimen of a polyp of the colon. Arrow indicates the vascular wall with amyloid substance (HE stain, $\times 200)$.

Colonoscopy revealed red mucosal lesions, compatible to colitis, and two polyps in the ascending colon. By histological examination, deposition of amyloid was detected in the perivascular region of the polyp with no malignant cells (Fig. 2). Since she did not have any further new bleeding event, she was discharged on May 5, 1991.

\section{Discussion}

Amyloidosis is one of the common complications of multiple myeloma. The diagnosis of amyloidosis depends on a histopathological finding of an appropriate specimen $(1,3)$. In some cases of amyloidosis with multiple myeloma, the amyloid substance has been deposited in the bone marrow (4), cardiac system $(5,6)$, or the intestinal wall (7). Although about $10 \%$ of the patients with multiple myeloma have amyloidosis (5), a more detailed study including biopsy of the tongue showed that $27 \%$ of the patients were complicated with amyloidosis (8). Initial symptoms and findings of amyloidosis with multiple myeloma are fatigue, body weight loss, pain, purpura, hepatomegaly and macroglossia (1). Colchicine and dimethyl sulfoxide are reported to be effective for amyloidosis $(9,10)$. In cases of amyloidosis, bleeding can occur from skin, oral cavity, gastrointestinal system and other organs $(1,2,8)$. In multiple myeloma, the bleeding tendency is due to the deficiencies of factor VIII, IX, X and other vitamin K-dependent clotting factors, intravascular coagulopathy, or the deposit of amyloid substance which causes fragility of tissue $(1,2)$. And it has also been reported that an impairment in fibrinogen conversion to fibrin, and increased fibrinolytic activity are observed in cases of multiple myeloma (2). Clinically significant bleeding was described in approximately $40 \%$ of patients with amyloidosis (2). In one autopsy series, massive hemorrhage was determined to be the cause of death in $3 \%$ of patients with multiple myeloma (11). In the present case, however, the data of PT, APTT, FDP and bleeding time remained normal. Therefore the deficiency of the factors, intravascular coagulopathy, thrombocytopenia or 


\section{Bleeding Tendency in Amyloidosis}

dysfunction of platelet were not likely responsible for this bleeding tendency. Further, there were no data suggestive of an increased fibrinolytic activity in the present case. The biopsy specimen from the polyp of the ascending colon showed a deposit of amyloid substance in perivascular region. Thus, the deposit to the vascular system might have caused the weakness of vascular walls, and subsequently the bleeding tendency. Therefore, in the case of bleeding tendency of amyloidosis or multiple myeloma, a deposit of amyloid substance in the vascular wall should be suspected, in addition to the defective coagulation factors.

As a therapy for the bleeding tendency of the present case, hemostatic agents were effective. Although an antifibrinolytic drug was thought not to be very effective because of the lack of data showing increased fibrinolytic activity, the two-drug combination therapy was effective. The effectiveness of these agents might also suggest that the bleeding tendency of the present case was due to the weakness of the vascular wall from the deposit of amyloid substance. These agents should be considered in cases of bleeding tendency which may be due to the deposit of amyloid substance.

\section{References}

1) Kyle RA, Greipp PR. Amyloidosis (AL). Mayo Clin Proc 58: 665, 1983.

2) Glaspy JA. Hemostatic abnormalities in multiple myeloma and related disorders. Hematol Oncol Clin North Am 6: 1301, 1992.

3) Reed SB, Morris GT. Amyloidosis; current approaches for diagnosis and treatment. J Ky Med Assoc 90: 68, 1992.

4) Limas C, Wright JR, Matsuzaki M, Calkins E. Amyloidosis and multiple myeloma. A reevaluation using a control population. Am J Med 54: 166, 1973.

5) Roberts WC, Waller BF. Cardiac amyloidosis causing cardiac dysfunction. Analysis of 54 necropsy patients. Am J Cardiol 52: 137, 1983.

6) Falk RH, Plehn JF, Deering T, et al. Sensitivity and specificity of the echocardiographic features of cardiac amyloidosis. Am J Cardiol 59: 418, 1987.

7) Williamson RCN. Primary amyloidosis of the rectum. Proc R Soc Med 65: 74, 1972.

8) Raubenheimer EJ, Dauth J, Pretorius FJ. Multiple myeloma and amyloidosis of the tongue. J Oral Pathol 17: 554, 1988.

9) Shirahama T, Cohen AS. Blockade of amyloid induction by colchicine in an animal model. J Exp Med 140: 1102, 1974.

10) Ravid M, Kedar (Keizman) I, Sohar E. Effect of a single dose of dimethyl sulfoxide on renal amyloidosis. Lancet 1: 730, 1977.

11) Kapadia SB. Multiple myeloma; a clinicopathologic study of 62 consecutively autopsied cases. Medicine 59: 380, 1980. 